\title{
Normal Luminal Bacteria, Especially Bacteroides Species, Mediate Chronic Colitis, Gastritis, and Arthritis in HLA-B27/Human $\beta_{2}$ Microglobulin Transgenic Rats
}

\author{
Heiko C. Rath, Hans H. Herfarth, Jack S. Ikeda, ${ }^{\star}$ Wetonia B. Grenther, Thomas E. Hamm, Jr., Edward Balish, ${ }^{\ddagger}$ Joel D. Taurog, ${ }^{\S}$ \\ Robert E. Hammer, ${ }^{\|}$Ken H. Wilson, ${ }^{*}$ and R. Balfour Sartor \\ Center of Gastrointestinal Biology and Disease, University of North Carolina, Chapel Hill, North Carolina 27599-7080; *Department of \\ Infectious Diseases, VA Medical Center, Duke University, Durham, North Carolina 27705; ${ }^{\ddagger}$ Department of Surgery, University of \\ Wisconsin Medical School, Madison, Wisconsin 53706-1532; and ${ }^{\S}$ Harold C. Simmons Arthritis Research Center and Department of \\ Internal Medicine, "Howard Hughes Medical Institute and Department of Biochemistry, Southwestern Medical Center, University of \\ Texas, Dallas, Texas 75235-8884
}

\begin{abstract}
Genetic and environmental factors are important in the pathogenesis of clinical and experimental chronic intestinal inflammation. We investigated the influence of normal luminal bacteria and several groups of selected bacterial strains on spontaneous gastrointestinal and systemic inflammation in HLA-B27 transgenic rats. Rats maintained germfree for 3-9 mo were compared with littermates conventionalized with specific pathogen-free bacteria. Subsequently, germfree transgenic rats were colonized with groups of five to eight bacteria that were either facultative or strictly anaerobic. Transgenic germfree rats had no gastroduodenitis, colitis, or arthritis, but developed epididymitis and dermatitis to the same degree as conventionalized rats. Colonic proinflammatory cytokine expression was increased in transgenic conventionalized rats but was undetectable in germfree and nontransgenic rats. Colitis progressively increased over the first 4 wk of bacterial exposure, then plateaued. Only transgenic rats colonized with defined bacterial cocktails which contained Bacteroides spp. had colitis and gastritis. Normal luminal bacteria predictably and uniformly induce chronic colonic, gastric and systemic inflammation in B27 transgenic F344 rats, but all bacterial species do not have equal activities. (J. Clin. Invest. 1996. 98:945-953.) Key words: experimental colitis - germfree • specific pathogen free $\bullet$ Bacteroides
\end{abstract}

\section{Introduction}

Both genetic and environmental factors have been documented in the pathogenesis of the idiopathic inflammatory bowel diseases (IBD), ${ }^{1}$ ulcerative colitis, and Crohn's disease (1). Substantial data from clinical observations and animal

\footnotetext{
Address correspondence to R. Balfour Sartor, Professor of Medicine, Microbiology and Immunology, Division of Digestive Disease, CB\#7080, Burnett-Womack Building, University of North Carolina at Chapel Hill, Chapel Hill, NC 27599-7080. Phone: 919-966-0149; FAX: 919-966-6842.

Received for publication 20 October 1995 and accepted in revised form 21 June 1996.
}

1. Abbreviations used in this paper: IBD, inflammatory bowel disease; IL-1RA, IL-1 receptor antagonist; MPO, myeloperoxidase; PG-PS, peptidoglycan-polysaccharide; SPF, specific pathogen free.

The Journal of Clinical Investigation

Volume 98, Number 4, August 1996, 945-953 models incriminate normal luminal bacteria or bacterial products in the initiation and perpetuation of chronic enterocolitis and associated systemic inflammation (2), although the critical bacterial components or antigen(s) are not yet known. Crohn's colitis and ileocolitis respond to treatment with metronidazole (3) and ciprofloxacin or clarithromycin can induce longlasting remission in Crohn's disease $(4,5)$. In addition, ciprofloxacin is effective as adjuvant therapy for ulcerative colitis (6). Subserosal injection of purified bacterial cell wall polymers, such as peptidoglycan-polysaccharide (PG-PS), induces chronic relapsing granulomatous enterocolitis with systemic inflammation in genetically susceptible rats $(7,8)$, while small bowel bacterial overgrowth causes spontaneous hepatobiliary inflammation and reactivates arthritis $(9,10)$. Antibiotics, especially those active against anaerobic bacteria, prevent and treat hepatobiliary disorders and arthritis in a bacterial overgrowth model and prevent indomethacin-induced enterocolitis (9-11). Finally, axenic Lewis rats raised in a sterile environment do not develop chronic intestinal inflammation after subcutaneous indomethacin injection, in contrast to littermates conventionalized with specific pathogen free (SPF) bacteria (12).

The lumen of the distal ileum and colon is a complex ecosystem composed of over 200 different bacterial species, dominated by anaerobes, which outnumber aerobes by a factor of $10^{3}$ (13). Recent evidence suggests that all enteric bacteria may not have equal abilities to induce and perpetuate inflammation (2). Several resident enteric bacterial species have been associated with Crohn's disease and ulcerative colitis, and certain strains have a preferential ability to induce chronic inflammation in animal models. Luminal concentrations of Bacteroides vulgatus (14) Eubacteria, Peptostreptococcus, and Coprococcus (15), and serum antibodies to the latter three bacteria (16) are specifically increased in Crohn's disease. Concentrations of facultative anaerobic bacteria, such as Streptococcus faecum (enterococcus, group D streptococci), are increased in ulcerative colitis patients, and functionally altered Escherichia coli have been implicated in the pathogenesis of ulcerative colitis (2). Furthermore, Bacteroides vulgatus plays an essential role in the pathogenesis of carrageenan-induced colitis in guinea pigs (17), and purified PG-PS polymers from Eubacteria, Peptostreptococcus, E. coli, and $S$. faecum can induce arthritis in susceptible rat strains $(2,18,19)$.

The MHC is a powerful determinant of genetically mediated immunoregulation. The MHC class I molecules are surface-expressed dimers composed of a highly polymorphic transmembrane $\alpha$ chain and an invariant $\beta$ chain, $\beta_{2^{-}}$ microglobulin $\left(\beta_{2} \mathrm{~m}\right)$, which present intracellularly generated antigen to CD8 T lymphocytes (20). In humans, several MHC alleles are associated with susceptibility to certain disease states. One of the strongest associations between the MHC 
and human disease is between HLA-B27, a MHC class I-molecule, and seronegative spondylarthropathies, especially ankylosing spondylitis and reactive arthritis (21). A number of observations associate intestinal inflammation and luminal bacteria with this group of disorders. A high prevalence of spondyloarthropathy is found in patients with IBD, certain enteropathogenic bacteria predictably trigger B27-associated reactive arthritis, extensive structural, and antigenic mimicry has been documented between enteric bacteria and the HLA-B27 molecule. Moreover, at least subclinical ileocolitis has been found in two-thirds of patients with spondyloarthropathies examined by ileocolonoscopy (22). A direct role for HLA-B27 in these disorders is strongly supported by the observation that rats transgenic for HLA-B27 spontaneously develop gastroduodenitis, colitis, arthritis, and spondylitis (23). Diarrhea, which develops between 5 and 20 wk of age, is consistently the earliest clinical manifestation. Arthritis usually follows the onset of colitis by several weeks $(23,24)$. A bacterial influence on intestinal and joint inflammation was demonstrated by the lack of colitis and arthritis in B27 transgenic rats raised under germfree conditions (25).

Although the initial study demonstrated that germfree B27 rats developed colitis upon introduction into a conventional or SPF environment (25), this phenomenon was not systematically investigated. The aims of the present study were to examine systematically the effects of introducing SPF luminal bacteria on the initiation and perpetuation of spontaneous gastrointestinal and systemic inflammation in germfree HLA-B27 transgenic rats, to characterize the kinetics of colonic inflammation after exposure to bacteria, to examine the cytokine profiles in the inflamed colonic tissues, and to determine whether some bacterial species have a dominant role in the pathogenesis of inflammation in this model.

\section{Methods}

Animals. Transgenic rats of the 33-3 line on an inbred F344 background, bearing 55 copies of the B27 gene and 66 copies of the human $\beta_{2}$ microglobulin gene (23), were cesarean-derived into a germfree (sterile) environment as previously described (25). The colony was maintained by mating hemizygous transgenic females with nontransgenic males. Transgenic rats were identified by dot blot hybridization as described $(23,26)$.

Experimental design. Transgenic $(n=89)$ and nontransgenic $(n=$ 38) littermates raised in a germfree environment were divided into two groups at 6-8 wk of age. One group (GF) remained in the sterile isolators until necropsy at 3, 4, 6, or 9 mo of age. The second group (CV) was conventionalized with SPF rat bacterial flora. Conventionalization was accomplished by housing the GF rats with SPF Fischer F344 rats purchased from Charles River Inc. (Raleigh, NC) for 4-12 $\mathrm{h}$, swabbing the mouths of GF rats with a homogenate of feces of SPF rats and placing bedding and feces from SPF rats into the $\mathrm{CV}$ rat cage. These rats were then maintained in a room dedicated to SPF rats. Subsequently, 26 additional 2-mo-old germfree transgenic rats were colonized with defined bacterial species as detailed below and maintained under gnotobiotic conditions for 1 mo before necropsy. All rats were monitored weekly for clinical evidence of diarrhea and arthritis, as detected by soiling of the perianal fur and ankle joint erythema and swelling, respectively. CV rats were serially weighed, and had ankle joint diameters measured with calipers (10) at least weekly.

Before necropsy all rats underwent final blinded clinical examination of body weight, joint diameters, degree of hair loss, and diarrhea, then were killed by $\mathrm{CO}_{2}$ asphyxiation within $3 \mathrm{~h}$ of removal from gnotobiotic isolators. Anticoagulated cardiac blood was taken for evaluation of white blood cell count, hemoglobin, and hematocrit. The cecum and colon were inspected grossly in a blinded fashion for evidence of intestinal wall thickness and scored on a scale ranging from 0 to $4+$, using a previously validated system $(7,8)$. The cecum, right colon, rectum, ileum, jejunum, duodenum, and stomach were fixed in $10 \%$ buffered formalin. Spleen and liver were weighed. Right colonic segments were snap frozen in iso-penthane for myeloperoxidase (MPO), protein and RNA assays.

Germfree conditions. GF rats were caged in Trexler flexible film isolators using standard techniques (27). The germfree state was monitored every 2 wk and at necropsy by fecal Gram stain and aerobic and anaerobic cultures of bedding and cecal contents.

Colonization with specific bacterial cocktails. At 2 mo of age, germfree transgenic rats were transferred into separate isolators and colonized with one of three different specific bacterial cocktails: Charles River Altered Schaedler (CRAS; $n=8)$, DESEP $(n=11)$, and DESEP-B $(n=7)$ (Table I). Transgenic control rats were either kept germfree $(n=8)$ or conventionalized with SPF bacteria $(n=8)$ as described above. A gnotobiotic rat colonized solely with CRAS flora (28) was obtained from Charles River Inc. Bacteria in the DESEP cocktail were isolated from Crohn's disease patients by Prof. Marteen Hazenberg, Erasmus University, Rotterdam, The Netherlands (18) (Eubacterium contortum and Peptostreptococcus productus) and by the Clinical Microbiology Laboratory of the University of North Carolina Hospitals, Chapel Hill, NC (E. coli and S. avium). S. faecium was provided by Dr. Steven Simpson, Glaxo-Wellcome, Research Triangle Park, NC (19). B. vulgatus is a gift from Dr. A. B. Onderdonk, Harvard University, Cambridge, MA, and originated from a guinea pig with carageenan-induced colitis (17). Colonization with DESEP and DESEP-B bacteria was accomplished by instilling $1 \mathrm{ml}$ of overnight cultures in brain-heart infusion, diluted in PBS, into the

Table I. Bacterial Cocktails Used for Colonization Purposes

\begin{tabular}{lll}
\hline \multicolumn{1}{c}{ CRAS* } & \multicolumn{1}{c}{ DESEP } & \multicolumn{1}{c}{ DESEP-B } \\
\hline CRBL \#360 Lactobacillus acidophilus & Streptococcus faecum (group D) & Streptococcus faecum (group D) \\
CRBL \#361 Lactobacillus salivarius & Escherichia coli & Escherichia coli \\
CRBL \#519 Bacteroides distasonis & Streptococcus avium & Streptococcus avium \\
CRBL \#356 fusiform-shaped bacterium & Eubacterium contortum & Eubacterium contortum \\
CRBL \#492 fusiform-shaped bacterium & Peptostreptococcus productus & Peptostreptococcus productus \\
CRBL \#500 fusiform-shaped bacterium & & Bacteroides vulgatus
\end{tabular}

CRBL \#502 fusiform-shaped bacterium

CRBL \#457 fusiform-shaped bacterium

*CRAS, Charles River Altered Schaedler. 
Table II. Histological Score to Quantify the Degree of Gastrointestinal Inflammation in B27 Transgenic Rats

\begin{tabular}{lccccccl}
\hline & \multicolumn{9}{c}{ Score } & & \multicolumn{1}{c}{ Add } \\
\cline { 2 - 5 } \multicolumn{1}{c}{ Criterion } & 0 & 1 & 2 & 3 & 4 & & $+0.5-+1$ for each \\
\hline Inflammatory cells & - & $\uparrow$ & $\uparrow \uparrow$ & $\uparrow \uparrow \uparrow$ & $\uparrow \uparrow \uparrow$ & ulcer \\
Goblet cells & - & $\downarrow$ & $\downarrow \downarrow$ & $\downarrow \downarrow \downarrow$ & $\downarrow \downarrow \downarrow$ & crypt abscess \\
Mucosa thickening & - & $\uparrow$ & $\uparrow \uparrow$ & $\uparrow \uparrow \uparrow$ & $\uparrow \uparrow \uparrow$ & \\
Submucosa cell infiltration & - & - & $\uparrow$ & $\uparrow \uparrow$ & $\uparrow \uparrow \uparrow$ & \\
Destruction of architecture & - & - & - & $\uparrow$ & $\uparrow \uparrow$ & \\
\hline
\end{tabular}

$\uparrow$, increased; $\downarrow$, decreased.

stomach and rectum of germfree transgenic rats. Germfree B27 transgenic rats were colonized with CRAS bacteria by introducing a CRAS flora rat into the germfree isolator and by swabbing their mouths and rectums with fecal homogenates from this rat. Each group of colonized rats was maintained under gnotobiotic conditions. Successful bacterial colonization was confirmed by culturing and Gram staining fecal pellets $1 \mathrm{wk}$ after inoculation and of the cecal content at necropsy.

Histology. Tissues were fixed in $10 \%$ neutral buffered formalin for at least $24 \mathrm{~h}$. Cross sectioned organs were embedded in paraffin, sectioned at $6-\mu \mathrm{m}$ thickness, and stained with hematoxylin and eosin. Coded samples were evaluated by a single observer (H.C. Rath) using light microscopy. Randomly selected sections were independently scored by a second blinded investigator (R.B. Sartor) with excellent correlation of scores. Cecal inflammation was quantitated by a histological score developed especially for this animal model (Table II). Gastric and small bowel inflammation were evaluated and scored from $0-4+$ using similar criteria. Histologic scores were correlated with MPO and IL- $1 \alpha$ tissue concentrations.

$M P O$ assay. Methods of tissue preparation and the assay of MPO activity (U/gram tissue weight) were previously described (29).

Radioimmunoassay. RIA was performed on supernatants of homogenized colonic tissues using the Rat Interleukin- $1 \alpha$ Test Kit ${ }^{\circledR}$ purchased from Cytokine Sciences, Inc. (Boston, MA) as previously described (7).

ELISA. For measuring IL-1 $\beta$ protein concentrations in the cecal tissue we performed ELISAs, using standard techniques developed by Dr. S. Poole (NI of Biological Standards and Controls, Hertfordshire, United Kingdom). Briefly, wells were coated with $100 \mu \mathrm{limmu-}$ noaffinity-purified sheep anti-rat IL-1 $\beta$ serum S4B3 and incubated overnight at $4^{\circ} \mathrm{C}$. Samples diluted 1:20 were added and incubated overnight at $4^{\circ} \mathrm{C}$. The 1:1,000 diluted biotinylated immunoaffinitypurified sheep anti-rat IL- $1 \beta$ polyclonal antibody was added and incubated for $1 \mathrm{~h}$. Avidin-horseradish peroxidase (Dako Corp., Carpinteria, CA) and 3.3',5.5'-tetramethylbenzidine liquid substrate system (Sigma, St. Louis, MO) were used as the conjugation enzyme and substrate.

Polymerase chain reaction analysis. For each sample, $1 \mu \mathrm{g}$ of total cellular RNA was reverse transcribed (30), in a total volume of 25 $\mu$ l. 1-2 $\mu$ l of cDNA sample were amplified in $50 \mu$ lof a reaction mixture containing $1 \times$ Taq buffer II (Perkin Elmer Cetus Corp., Norwalk, CT); $1.5 \mathrm{mM} \mathrm{MgCl} ; 0.2 \mu \mathrm{M}$ (IFN- $\gamma$, TNF- $\alpha$, IL-6), $0.1 \mu \mathrm{M}$ (IL-1 $\beta$, IL-1 receptor antagonist [IL-1RA]), $0.4 \mu \mathrm{M}$ ( $\beta$-Actin) or $0.5 \mu \mathrm{M}$ (IL$1 \alpha$ ) of each of $5^{\prime}$ and $3^{\prime}$ primers and $1 \mathrm{U}$ of Taq polymerase (Perkin Elmer Cetus Corp.). Samples were heated for $4 \mathrm{~min}$ at $94^{\circ} \mathrm{C}$ and the following cycles were conducted at $94^{\circ} \mathrm{C}$ for $45 \mathrm{~s}, 60^{\circ} \mathrm{C}$ or $58^{\circ} \mathrm{C}$ for $45 \mathrm{~s}$, $72^{\circ} \mathrm{C}$ for $1.5 \mathrm{~min}$. Negative controls without cDNA were amplified with each PCR experiment. To confirm the log-linearity of the amplification process, aliquots of the samples were taken at different cycles and analyzed by electrophoresis on a $2 \%$ agarose gel containing ethidium bromide. Primers specific for rat cytokines were constructed according to published sequences (30-37, Feeser, W., and B.D. Fremark; GenBank, Accession *\#M98820): (Sense Primer, Antisense Primer) IFN- $\beta$ (5'- AAG ACA ACC AGG CCA TCA GCA-3', 5' AGC CAC AGT GTG AGT TCA GTC-3'), TNF- $\alpha$ (5' - CAC CAT GAG CAC GGA AAG CA-3', 5'- GCA ATG ACT CCA AAG TAG ACC-3'), IL-6 (5' - CTT CCA GCC AGT TGC CTT CT- $3^{\prime}, 5^{\prime}$ GAG AGC ATT GGA AGT TGG GG-3'), IL-1 $\alpha$ (5'- TCC TGT GAC TCT CAA AGT CTC-3', 5'- ATG CGA GTG ACT TAG GAC GA-3'), IL-1 $\beta$ (5' - GCT ACC TAT GTC TTG CCC GT-3', 5'GAC CAT TGC TGT TTC CTA GG-3'), IL-1 RA (5' - CTG GGA TAC TAA CCA GAA GAC C-3', 5' - TGG TGT GTT GGT GAG GCT CAC - $\left.3^{\prime}\right), \beta$ - Actin (5'- ACC ACA GCT GAG AGG GAA ATC G-3' ' 5' - AGA GGT CTT TAC GGA TGT CAA CG-3'). Authenticity of the PCR products was confirmed using specific restriction enzymes.

Statistical methods. All data are expressed as mean \pm SEM. To test for differences between the groups, the ANOVA was used. Samples with equal distribution were compared using the $t$ test. To compare nominal variables between groups the $\chi^{2}$-test was performed. $P<$ 0.05 was considered statistically significant.

\section{Results}

\section{Inflammation in germfree $v$ s conventionalized transgenic rats}

The data shown are from 6-mo-old rats, but are representative of all other rats euthanized over the study period of 3-9 mo.

Clinical features. Transgenic CV rats $(n=21)$ were the only group to show diarrhea or clinical signs of arthritis $(83 \%$ incidence of both diarrhea and arthritis in the transgenic CV group vs $0 \%$ in the transgenic germfree $[n=12]$ and nontransgenic $\mathrm{CV}[n=10]$ littermates $[P<0.005])$. The onset of the nonbloody diarrhea and arthritis was variable in the CV transgenic rats, but achieved an incidence of $83 \%$ by 3 mo of age. Arthritis followed an undulating pattern with spontaneous remission, and was relatively mild.

There were no differences in weight gain, joint diameters, or the incidence of hair loss, dermatitis, orchitis, and epididymitis in transgenic conventionalized rats compared with transgenic germfree littermates (hair loss occurred in $100 \%$ of transgenic

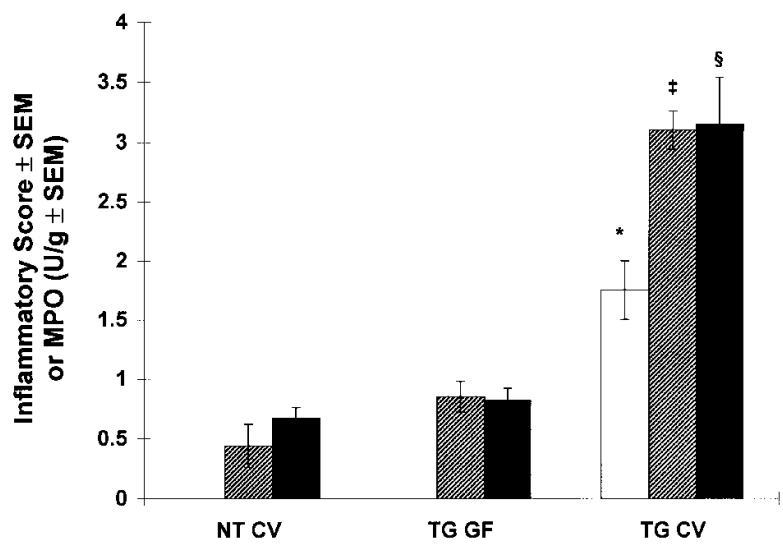

Figure 1. Lack of colonic inflammation in germfree B27 transgenic rats in contrast to SPF rats. Gross $(\square)$ and histological (包) signs of inflammation were graded in a blinded fashion using a score from $0-4$ as outlined in the Methods section. Tissue myeloperoxidase activity ( $\mathbf{\square})$ was normalized against the colonic tissue weight. ${ }^{*} P<0.001,{ }^{\ddagger} P<$ $0.0001,{ }^{\S} P<0.005$ vs transgenic GF. $N T$, nontransgenic; $T G$, HLA$\mathrm{B} 27 / \beta 2 \mathrm{~m}$ transgenic; $C V$, conventionalized with specific pathogen free enteric bacteria; $G F$, germfree (sterile). 

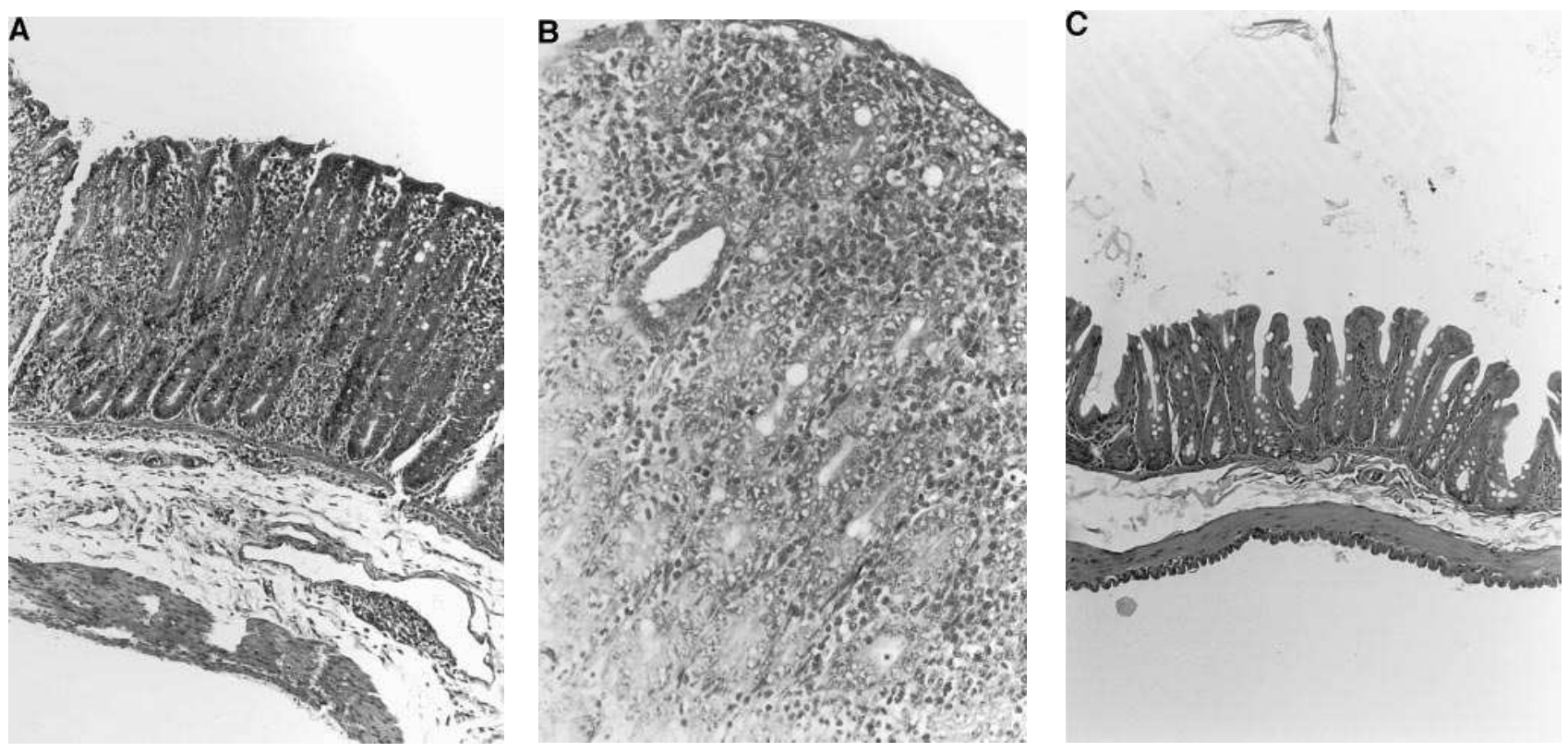

Figure 2. Histological features of cecal inflammation in B27 transgenic CV or GF rats. $(A)$ The cecum of transgenic rats conventionalized with SPF bacteria exhibits thickening of the mucosa and inflammatory cell infiltration with predominantly mononuclear cells and scattered eosinophils but only occasional neutrophils $(\times 100)$. (B) Higher magnification $(\times 400)$ shows increased numbers of mononuclear cells in the lamina propria and a crypt abscess. $(C)$ In contrast, germfree transgenic rats show normal cecal histology with normal crypts, abundant goblet cells, a small number of lamina propria mononuclear cells, no thickening of the mucosa, and no ulcerations or crypt abscesses $(\times 100)$.

rats in each group by 6 mo of age and testicular inflammation was present in $100 \%$ of males).

Colonic inflammation. At necropsy the intestine was grossly evaluated for inflammatory lesions in a blinded fashion. Transgenic $\mathrm{CV}$ rats had significantly more thickening of the cecal and colonic walls than transgenic GF and nontransgenic $\mathrm{CV}$ littermates $(P<0.001$; Fig. 1$)$; the latter two groups had no detectable lesions. Adenomatous polyps and adenocarcinomas were not seen.

Similar to the gross observations, transgenic $\mathrm{CV}$ rats had significantly more histologic cecal inflammation $(P<0.0001)$ than GF and CV nontransgenic littermates (Fig. 1). Histologic inflammatory scores were not significantly different between GF transgenic and nontransgenic CV rats. Cecal inflammation in $\mathrm{CV}$ transgenic rats was characterized by predominantly mononuclear cell infiltration of the lamina propria with scattered eosinophils and very few neutrophils (Fig. 2, $A$ and $B$ ). Scattered foci of these inflammatory cells only rarely extended to the submucosa in the most severely inflamed regions. In addition, transgenic $\mathrm{CV}$ rats had marked thickening of the mucosa, crypt hyperplasia with rare crypt abscesses, reduction of mucus-secreting goblet cells, and early ulcerations limited to the mucosa, but no granulomas or neoplasms. In contrast, colonic sections from GF transgenic rats showed almost no evidence of inflammation, with thin cecal walls, abundant goblet cells, no cellular infiltration and no crypt abnormalities (Fig. 2 $C)$. These lesions were similar to those previously described in conventionally housed B27 transgenic rats (23-25).

To quantitate the degree of neutrophilic or eosinophilic cell infiltration in the intestine, tissue MPO activity was measured in the proximal transverse colon. Colonic MPO activity was increased in transgenic $\mathrm{CV}$ rats $(P<0.005)$ compared with transgenic GF and nontransgenic rats; no differences were seen between the transgenic GF and nontransgenic groups (Fig. 1).
Tissue IL-1 $\alpha$ protein concentrations in the transverse colon were increased in transgenic CV rats $(9,575 \pm 1,502 \mathrm{pg} / \mathrm{gram}$ tissue) compared with undetectable levels in transgenic GF and nontransgenic $\mathrm{CV}$ rats $(<20 \mathrm{pg} / \mathrm{gram} ; P<0.0001)$. Elevated mRNA levels of the monokines IL- $1 \alpha$, IL-1 $1 \beta$, and TNF- $\alpha$ were demonstrated in the inflamed colonic tissues of the transgenic CV rats but were undetectable in transgenic GF rats (Fig. 3). In addition, we observed an increase in IL-6 mRNA expression in some of the transgenic $\mathrm{CV}$ animals (data not shown).

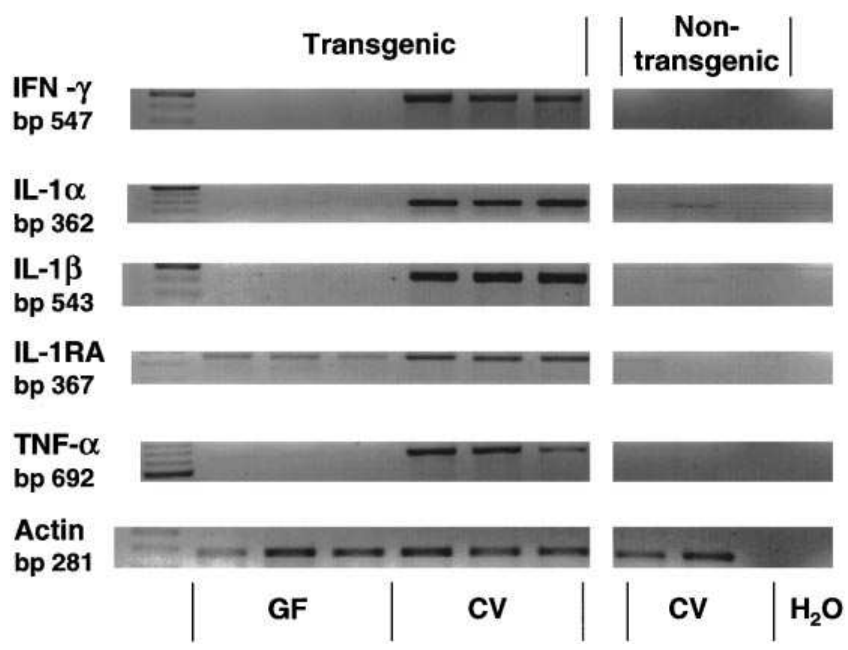

Figure 3. Expression of IL-1 $\alpha$, IL-1 $\beta$, IL-1RA,TNF- $\alpha$, and IFN- $\gamma$ mRNA in colonic tissues of transgenic GF and CV rats and nontransgenic CV control animals. Total RNA was reverse transcribed and amplified for various cycles by the polymerase chain reaction (23-40 cycles depending on the cytokine and according to the methods described above). $\beta$-actin was used to verify equal loading of cDNA. 
All colons had detectable IL-1RA expression, which was increased after bacterial exposure. Low levels of IL- $1 \alpha$ and IL-1 $\beta$ mRNA expression were occasionally seen in nontransgenic $\mathrm{CV}$ rats. IFN- $\gamma$ mRNA was strongly elevated in rats with intestinal inflammation compared with the noninflamed tissues of transgenic GF and nontransgenic CV rats (Fig. 3).

Gastric and small intestinal inflammation. The stomach of transgenic $\mathrm{CV}$ rats was inflamed predominantly in the antrum (Fig. 4, $A$ and $B$ ) and less extensively in the proximal glandular portion. As in the cecum, the blinded histologic scores of inflammation (Fig. 5) in these areas of the stomach were significantly increased in transgenic $\mathrm{CV}$ rats $(P<0.0001)$ compared with GF littermates. GF transgenic and CV nontransgenic rats had similar histologic scores. No inflammation was detectable in the squamous portion of the stomach in any group.

Duodenal inflammation (Fig. 5) in GF transgenic rats was less than in $\mathrm{CV}$ littermates $(P<0.005)$ and was not different from $\mathrm{CV}$ nontransgenic rats. No consistent inflammatory changes were seen in the jejunum and ileum of CV transgenic rats and, when present, were less extensive than in the duodenum and colon. There were no significant differences in ileitis in GF and CV transgenic rats (data not shown).

Systemic inflammation. Hemoglobin concentrations, hematocrits, spleen, and liver weights (data not shown) showed no significant difference between $\mathrm{CV}$ and GF transgenic animals. Transgenic CV rats had the highest degree of leukocytosis $(16.2 \pm 0.9 ; P<0.001)$, but GF transgenic rats also had ele- vated white blood cell concentrations $(11.1 \pm 0.4)$ relative to nontransgenic controls $(5.3 \pm 0.3 ; P<0.05)$.

\section{Time course of inflammation after bacterial exposure}

No significant differences in gross, histologic, or biochemical parameters of chronic intestinal inflammation were noted among transgenic $\mathrm{CV}$ rats examined between 3 mo and 9 mo of age (after 1.5-7 mo of bacterial exposure). To determine the kinetics of the onset of inflammation after bacterial colonization, transgenic rats were observed for 1-4 wk after exposure to SPF bacteria ( $n=5 /$ group; Fig. 6 ). Colonic MPO levels progressively increased and were significantly elevated at 4 wk $(P<$ $0.05)$. Gross and histologic assessment of colonic inflammation followed the same time course (data not shown). Arthritis was not seen during this brief period of bacterial exposure.

\section{Colonization of transgenic rats with defined bacterial cocktails}

To determine whether normal flora bacteria differ in their ability to induce inflammation, B27 transgenic rats were colonized with groups of defined bacteria. Neither diarrhea nor arthritis was observed in the gnotobiotic groups and GF or CV controls over the 1 mo of bacterial exposure. Cecal inflammation occurred in CRAS- and DESEP-B-colonized transgenic animals, but not in DESEP and GF rats, as shown by gross and histologic observations as well as tissue MPO and IL-1 $\beta$ protein concentration (Fig. 7 and Table III). Colitis was consistently highest in the DESEP-B group of gnotobiotic rats by all
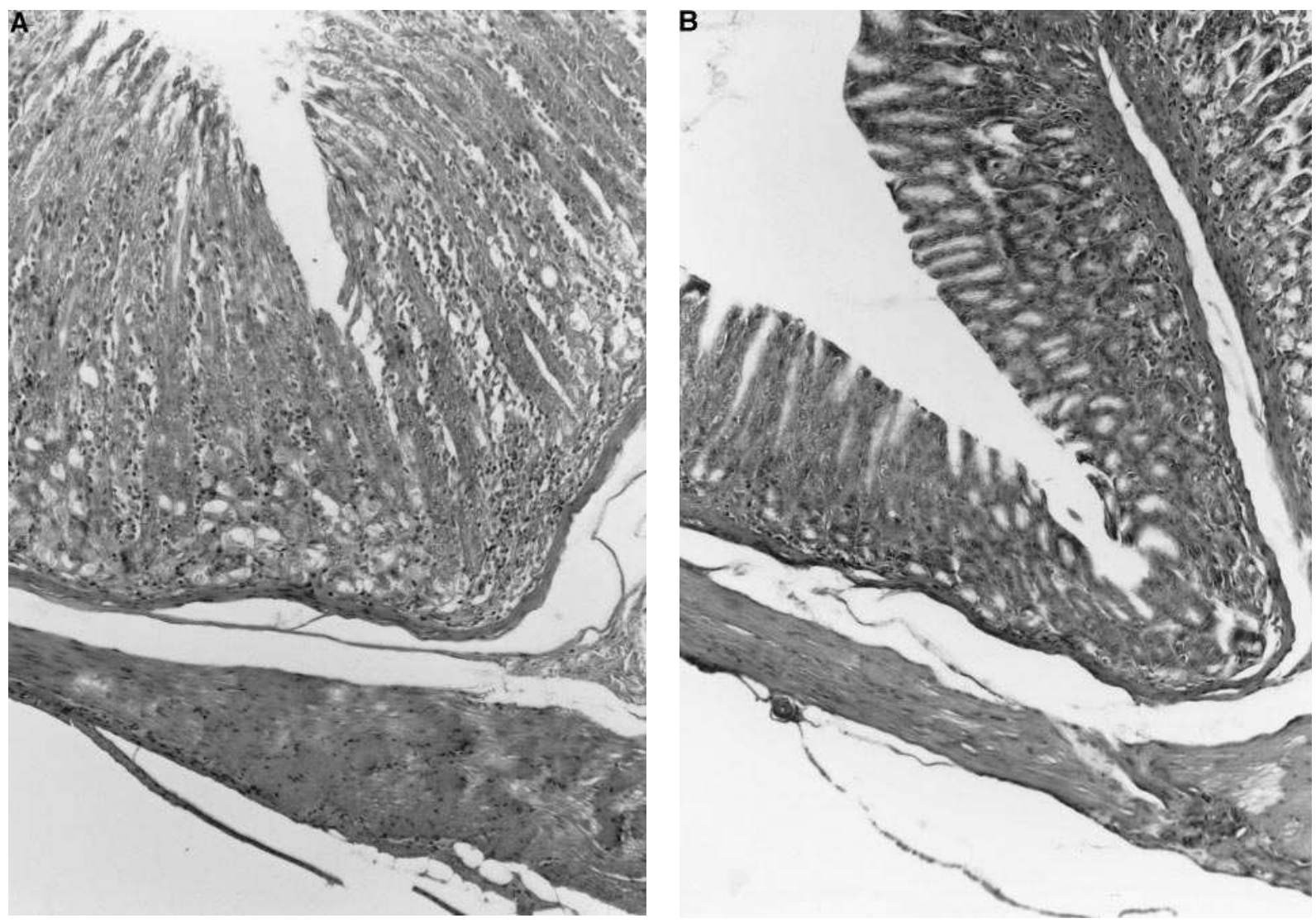

Figure 4. Histology of gastric inflammation in B27 transgenic CV and GF rats. $(A)$ The mucosa in the antrum in transgenic rats exposed to bacteria was thickened and infiltrated with predominantly mononuclear cells and scattered eosinophils $(\times 100)$. $(B)$ In contrast no inflammation was seen in germfree transgenic rats $(\times 100)$. 


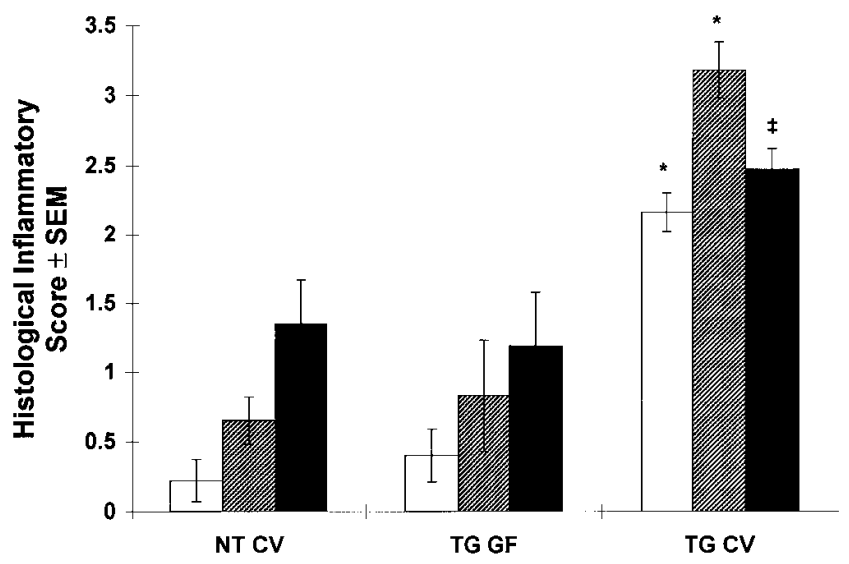

Figure 5. Gastritis ( $\square$ glandular portion and $\square$ antrum) and duodenitis ( $\mathbf{\square})$ in B27 transgenic CV and GF rats. Histological signs of inflammation was graded in a blinded fashion using a score from $0-4$ as outlined in the Methods section. $* P<0.0001$ and ${ }^{\ddagger} P<0.005$ vs transgenic GF.

observed parameters. Gastritis was evident histologically in all gnotobiotic groups but was significantly higher than GF rats only in DESEP-B animals (Fig. 7); however, gastritis and cecal inflammation in the DESEP-B group did not reach the degree of inflammation observed in transgenic $\mathrm{CV}$ rats. The white blood cell count was not elevated over GF values in any gnotobiotic group, in contrast to transgenic $\mathrm{CV}$ rats.

\section{Discussion}

It was previously reported that B27 transgenic rats raised in an environment free of bacteria do not develop colitis or arthritis (25). However, even in the germfree state, these rats develop orchitis, alopecia, and dermatitis with incidence and severity similar to that of conventionalized B27 transgenic rats. The present study, which was conducted in a different gnotobiotic facility, confirms the previous observations and extends these results by: (a) demonstrating that transgenic rats conventionalized with SPF enteric bacteria develop arthritis; $(b)$ documenting the kinetics of the inflammatory response after bacterial colonization; $(c)$ elucidating a selective cytokine profile of the inflamed colon; $(d)$ demonstrating a requirement for bacteria in the pathogenesis of gastroduodenal inflammation; and (e) showing that some resident enteric bacteria are more active than others in inducing inflammation in this model.

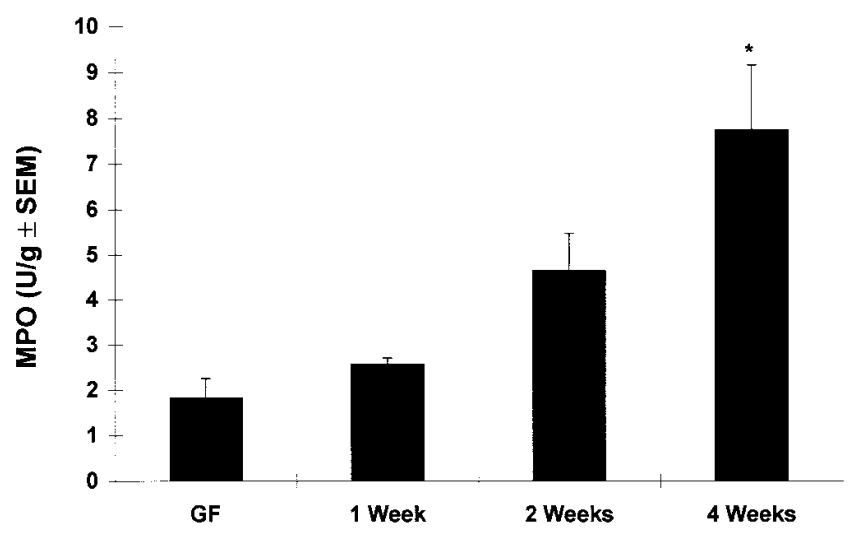

Figure 6. Time course of colitis in B27 transgenic rats conventionalized with SPF bacteria. The degree of colitis was measured by colonic myeloperoxidase $(M P O)$ concentrations. $* P<0.01$ vs nontransgenic $\mathrm{CV}$, transgenic GF, and transgenic $\mathrm{CV}$ after 1 wk of exposure.

These observations strongly incriminate normal flora bacteria in the pathogenesis of chronic intestinal inflammation in genetically susceptible hosts, since pathogenic bacteria, viruses, and parasites were absent in transgenic rats that developed colitis, gastroduodenitis, and arthritis and defined, simplified microflora induced similar lesions. These results agree with previous observations that germfree Lewis rats treated with subcutaneous indomethacin have attenuated, self-limited small intestinal inflammation and no evidence of cecal or systemic inflammation (12). A similar requirement for normal flora bacteria has been observed in IL-2 and IL-10-deficient mice, which have attenuated inflammation in SPF environments $(38,39)$, compared with conventional conditions. Moreover, IL-2-deficient mice have no clinical or histologic colitis in the germfree state (38). These results are entirely consistent with observations that antibiotics, especially those which are effective against anaerobes, prevent experimental enterocolitis in several animal models and are therapeutic for Crohn's colitis and indomethacin-induced enteropathy $(3,9,11,40-42)$.

Our results indicate that not all enteric bacteria have equal abilities to induce gastrointestinal inflammation. HLA-B27 transgenic rats colonized with a combination of $E$. contortum, $P$. productus, E. coli, $S$. faecum, and $S$. avium isolated from Crohn's disease patients (DESEP) unexpectedly had no significant increase in colitis or gastritis over that seen in GF rats, despite the fact that these specific strains were chosen because of their postulated role in IBD (2) and because they represent

Table III. Colitis, as Determined by the Gross Gut Score, Myeloperoxidase, and IL-1 $\beta$ Protein Concentration in Cecal Tissue from Transgenic Rats Colonized with Different Bacterial Floras

\begin{tabular}{lccccc}
\hline & GF & CRAS & DESEP & DESEP-B & CV \\
\hline Gross Gut Score & $0 \pm 0$ & $0 \pm 0$ & $0 \pm 0$ & $0.39 \pm 0.1^{*}$ & $1.19 \pm 0.1$ \\
Myeloperoxidase & $0.18 \pm 0.02$ & $0.50 \pm 0.04^{\S}$ & $0.30 \pm 0.04$ & $0.55 \pm 0.09^{\ddagger}$ & $1.24 \pm 0.14$ \\
$\quad$ U/gram tissue & $494 \pm 83$ & $2615 \pm 757^{\Uparrow}$ & $1237 \pm 288$ & $10626 \pm 1578 \|$
\end{tabular}

$\mathrm{pg} / \mathrm{gram}$ tissue

${ }^{*} P<0.001$ vs GF, CRAS, and DESEP; ${ }^{\ddagger} P<0.01$ vs DESEP, $P<0.0005$ vs GF, and $P<0.005$ vs $\mathrm{CV} ;{ }^{\S} P<0.0001$ vs GF; $\|^{P}<0.0001$ vs DESEP and GF, $P<0.001$ vs CRAS; ${ }^{\mathbb{I}} P<0.05$ vs GF. Mean \pm SEM. See Table I for description of DESEP and DESEP-B. 


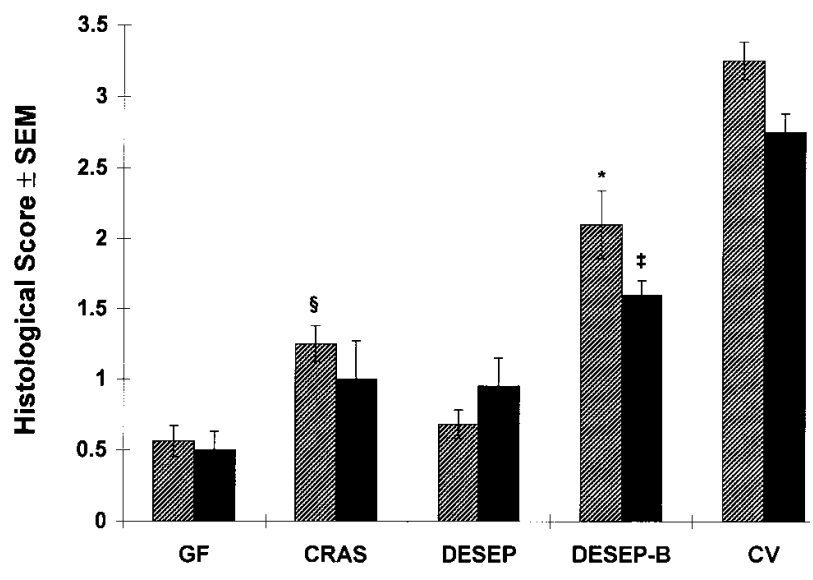

Figure 7. Histologic inflammatory scores of the cecum (四) and antrum (ם) revealed significant differences between DESEP-B vs DESEP or GF rats. CRAS colonized animals had higher histologic inflammatory scores in the cecum, but not in the antrum, than GF rats. ${ }^{*} P<0.001$ vs DESEP, GF, and $\mathrm{CV} ;{ }^{\ddagger} P<0.05$ vs DESEP and $P<$ 0.0001 vs GF and $\mathrm{CV} ;{ }^{\S} P<0.05$ vs GF and $P<0.0001$ vs CV. See Table I for descriptions of CRAS, DESEP, and DESEP-B.

some of the most common aerobic and anaerobic constituents of the normal enteric flora (13). PG-PS from the first four of these bacterial strains induces arthritis after peritoneal injection $(18,19)$, and intramurally-injected PG-PS from $S$. faecum causes chronic granulomatous enterocolitis (8). It is possible that increased serum antibodies to Eubacteria and Peptostreptococci in Crohn's disease patients (16) merely reflect enhanced mucosal absorption and/or heightened host immunoresponsiveness to these bacterial species, which are selectively increased in this disorder (15).

Significantly increased colitis and gastritis in transgenic rats additionally colonized with $B$. vulgatus (DESEP-B) strongly implicate this organism in the pathogenesis of chronic intestinal inflammation. Another Bacteroides strain (B. distasonis) is a component of the CRAS flora, which induced an intermediate degree of colitis in our study. These observations are consistent with increased luminal concentrations of Bacteroides spp. in Crohn's disease patients, and the ability of metronidazole to treat Crohn's colitis (3), and, colitis and gastritis in B27 transgenic rats conventionalized with SPF bacteria (40). Of therapeutic importance, metronidazole administration for up to 6 mo chronically suppresses luminal concentrations of Bacteroides spp., and the therapeutic efficacy of this antibiotic in Crohn's disease closely correlates with fecal Bacteroides concentrations (14). Similarly, Lichtman et al. (9) showed that chronic metronidazole therapy eliminated Bacteroides spp. and prevented hepatobiliary inflammation in rats with jejunal self-filling blind loops. In a series of experiments, Onderdonk et al. (17) demonstrated that $B$. vulgatus was the dominant bacterial stimulus in carrageenan-induced colitis in guinea pigs. Furthermore, Bacteroides fragilis enterotoxin increases mucosal permeability and epithelial internalization of enteric bacteria (43). Together, these results demonstrate a consistent role for Bacteroides spp., especially B. vulgatus, in the pathogenesis of chronic intestinal inflammation. However, inflammation in the DESEP-B groups was less than littermates conventionalized with SPF bacteria, suggesting that additional bacterial interactions are involved in the complex microenvi- ronment of the conventional host. It is conceivable that some bacterial strains protect against gastrointestinal inflammation while others have a predominantly aggressive role, probably with synergistic activities. Furthermore, the difference between gastrointestinal inflammation in rats colonized with CRAS flora and SPF conventionalized rats indicate that, even though the CRAS flora were used to initially populate the majority of commercially available rodents in the United States (28), SPF rats have evolved a functionally distinct flora.

In view of the requirement for luminal bacteria in the genesis of intestinal inflammation, the consistent presence of gastroduodenitis and the relatively infrequent and mild distal ileitis is somewhat surprising. The stomach and proximal small intestine are mainly colonized by aerobic bacteria, whereas high concentrations of predominantly anaerobic bacteria are in intimate contact with the mucosa of the distal ileum, cecum, and colon (13). But the proximal gastrointestinal tract of rats is exposed to high concentrations of swallowed aerobic and anaerobic bacteria from oropharyngeal secretions, food, and ingested feces. Although gastric acid kills most of these ingested bacteria, nonviable bacterial components such as PG-PS polymers are capable of inducing and perpetuating intestinal and systemic inflammation $(2,10,44)$. Furthermore, a focus of inflammation in the stomach and duodenum with relative sparing of the ileum is a consistent feature of the inflammatory response in IL-10, IL-2, TGF- $\beta$, and G protein-deficient mice $(38,39,45,46)$, and histologic evidence of antral gastritis occurs in up to $60 \%$ of Crohn's disease patients (47). Although we did not observe consistent gross or histologic evidence of ileal inflammation in the B27 transgenic rats, Aiko and Grisham (48) showed increased ileal MPO concentrations and dry weights but no increased ileal mucosal permeability in these rats.

The profile of cytokines and biochemical markers in B27 transgenic rats exposed to enteric bacteria suggests that mechanisms of tissue injury are similar to those described in human $\operatorname{IBD}(1,49)$. Increased expression of the monokines IL- $1 \alpha$, IL-1 $\beta$, IL-1RA, TNF- $\alpha$, and IL-6 in the inflamed colons of transgenic rats exposed to bacteria incriminate activated macrophages, whereas IFN- $\gamma$ is a product of activated $\mathrm{T}$ lymphocytes and natural killer cells. Histologic analysis of the inflamed colonic tissues demonstrates infiltrations of macrophages and lymphocytes. Elevated tissue MPO concentrations could be a consequence of infiltration by either neutrophils or eosinophils (29), although the latter cell type was seen far more frequently on histologic assessment than the former. Similar profiles of cytokines have been described in human $\operatorname{IBD}(1,49)$ and numerous animal models of experimental intestinal inflammation (50).

As previously observed (25), dermatitis and epididymitis were not dependent on bacterial colonization. In addition, peripheral blood white blood cell levels were slightly but significantly higher in GF transgenic rats than in noninflammatory nontransgenic controls, probably as a consequence of ongoing dermatitis and epididymoorchitis. It remains to be determined whether these systemic inflammatory lesions are totally independent of bacterial stimulation, or whether they arise from exposure to small concentrations of bacterial cell wall components and antigens ingested in autoclaved rat chow, bedding, and water.

The relationship between luminal bacteria or bacterial products, colitis, and joint inflammation is well established (2, $7,8,10,19,21,22,51-53)$. Oligoarticular peripheral arthritis is associated with ulcerative colitis, Crohn's disease (especially of 
the colon), and a number of enteric infections. The appearance of arthritis after diarrhea in B27 transgenic CV rats agrees with previous observations (23-25) and further supports a central role for intestinal inflammation in the spondyloarthropathies. One hypothesis that accounts for this role is that enteric bacteria and bacterial products such as LPS, PG-PS, FMLP, and membrane antigens are absorbed to a greater degree during intestinal inflammation, leading to systemic distribution of these phlogistic bacterial components and subsequent extraintestinal inflammation, such as arthritis $(2,10,22)$. This hypothesis is supported by increased mucosal uptake of luminal PG-PS after experimental colonic or jejunal injury in the acetic acid and jejunal bacterial overgrowth models, respectively $(54,55)$, reactivation of arthritis by systemically injected PG-PS or LPS $(51,52)$, and the presence of bacterial antigens within synovial leukocytes in patients with B27-associated reactive arthritis $(56,57)$.

In summary, this study indicates that normal luminal bacteria play an important role in the pathogenesis of spontaneous colitis, gastroduodenitis, and peripheral arthritis in genetically susceptible B27 transgenic rats, but that not all resident bacterial species have equal abilities to induce inflammation. Identification of the subpopulations of luminal bacteria that exert a dominant role in induction of colitis has important therapeutic implications for IBD patients. Further studies of B27 transgenic rats should help determine whether Bacteroides spp. have a unique, essential role and whether there are other bacterial strains that have independent, synergistic or even protective activities.

\section{Acknowledgments}

The authors gratefully acknowledge the expert technical support of Diane E. Bender, Roger Brown, Lisa C. Holt and Sanjib Mohanty, and thank Drs. Andrew B. Onderdonk (Harvard University, Cambridge, MA), Marteen Hazenberg (Erasmus University, Rotterdam) and Peter Guilligan (University of North Carolina, Chapel Hill, NC) for supplying specific bacterial strains.

This work was supported by United States Public Health Service grants DK 34989, DK 40249, DK 47692 and AR 38319, the Crohn's and Colitis Foundation of America and the Deutsche Forschungsgemeinschaft Ra 671/1-1 and He 2379/1-1.

\section{References}

1. Sartor, R.B. 1995. Current concepts of etiology and pathogenesis of ulcerative colitis and Crohn's disease. Gastroenterol. Clin. North Am. 24:475-506.

2. Sartor, R.B. 1995. Microbial factors in the pathogenesis of Crohn's disease, ulcerative colitis and experimental intestinal inflammation. In Inflammatory Bowel Disease. J.B. Kirsner and R.G. Shorter, editors. Williams \& Wilkins, Baltimore, MD. 96-124.

3. Sutherland, L., J. Singleton, J. Sessions, S. Hanauer, E. Krawitt, G. Rankin, R. Summers, H. Mekhjian, N. Greenberger, M. Kelly, et al. 1991. Double blind, placebo controlled trial of metronidazole in Crohn's disease. Gut. 32: 1071-1075.

4. Peppercorn, M.A. 1993. Is there a role for antibiotics as primary therapy in Crohn's ileitis? J. Clin. Gastroenterol. 17:235-237.

5. Graham, D.Y., M.T. Al-Assi, and M. Robinson. 1995. Prolonged remission in Crohn's disease following therapy for Mycobacterium paratuberculosis infection. Gastroenterology. 108:826a. (Abstr.)

6. Turunen, U. 1994. A double-blind, placebo-controlled, six-month ciprofloxacin treatment improves prognosis in ulcerative colitis. Gastroenterology. 106:786a. (Abstr.)

7. McCall, R.D., S. Haskill, E.M. Zimmermann, P.K. Lund, R.C. Thompson, and R.B. Sartor. 1994. Tissue interleukin 1 and interleukin-1 receptor antagonist expression in enterocolitis in resistant and susceptible rats. Gastroenterology. 106:960-972.

8. Sartor, R.B., W.J. Cromartie, D.W. Powell, and J.H. Schwab. 1985. Gran- ulomatous enterocolitis induced in rats by purified bacterial cell wall fragments. Gastroenterology. 89:587-595.

9. Lichtman, S.N., J. Keku, J.H. Schwab, and R.B. Sartor. 1991. Hepatic injury associated with small bowel bacterial overgrowth in rats is prevented by metronidazole and tetracycline. Gastroenterology. 100:513-519.

10. Lichtman, S.N., J. Wang, R.B. Sartor, C. Zhang, D.E. Bender, F.G. Dalldorfer, and J.H. Schwab. 1995. Reactivation of arthritis induced by small bowel bacterial overgrowth in rats: role of cytokines, luminal bacteria and bacterial polymers. Infect. Immun. 63:2295-2301.

11. Yamada, T., E. Deitch, R.D. Specian, M.A. Perry, R.B. Sartor, and M.B. Grisham. 1993. Mechanisms of acute and chronic intestinal inflammation induced by indomethacin. Inflammation. 17:641-662.

12. Sartor, R.B., D.E. Bender, T. Grenther, and L.C. Holt. 1994. Absolute requirement for ubiquitous luminal bacteria in the pathogenesis of chronic intestinal inflammation. Gastroenterology. 104:767a. (Abstr.)

13. Donaldson, R.M., Jr. 1981. Normal bacterial population of the intestine and their relation to intestinal function. N. Engl. J. Med. 270:938-943.

14. Krook, A., B. Lindstrom, J. Kjellander, G. Jarnerot, and L. Bodin. 1981 Relation between concentrations of metronidazole and Bacteroides spp in faeces of patients with Crohn's disease and healthy individuals. J. Clin. Pathol. 34:645-650.

15. van de Merwe, J.P., A.M. Schroder, F. Wensinck, and M.P. Hazenberg. 1988. The obligate anaerobic faecal flora of patients with Crohn's disease and their first-degree relatives. Scand. J. Gastroenterol. 23:1125-1131.

16. Auer, I.O., A. Roder, F. Wensinck, J.P. van de Merwe, and H. Schmidt. 1983. Selected bacterial antibodies in Crohn's disease and ulcerative colitis. Scand. J. Gastroenterol. 18:217-223.

17. Onderdonk, A.B., M.L. Franklin, and R.L. Cisneros. 1981. Production of experimental ulcerative colitis in gnotobiotic guinea pigs with simplified microflora. Infect. Immun. 32:225-231.

18. Severijnen, A.J., R. van Kleef, M.P. Hazenberg, and J.P. van de Merwe. 1989. Cell wall fragments from major residents of the human intestinal flora induce chronic arthritis in rats. J. Rheumatol. 16:1061-1068.

19. Stimpson, S.A., R.R. Brown, S.K. Anderle, D.G. Klapper, R.L. Clark, W.J. Cromartie, and J.H. Schwab. 1986. Arthropathic properties of cell wall polymers from normal flora bacteria. Infect. Immun. 51:240-249.

20. Abbas, A.K., A.H. Lichtman, and J.S. Pober. 1994. The major histocompatibility complex. In Cellular and Molecular Immunology. A.K. Abbas, A.H. Lichtman, and J.S. Pober, editors. W.B. Saunders Co., Philadelphia. 96-114.

21. Inman, R.D., and R.H. Scofield. 1994. Etiopathogenesis of ankylosing spondylitis and reactive arthritis. Curr. Opin. Rheumatol. 6:360-370.

22. Sartor, R.B., and S.N. Lichtman. 1993. Mechanisms of systemic inflammation associated with intestinal injury. In Inflammatory Bowel Disease: From Bench to Bedside. S.R. Targan and F. Shanahan, editors. Williams \& Wilkins, Baltimore, MD. 210-229.

23. Hammer, R.E., S.D. Maika, J.A. Richardson, J.P. Tang, and J.D. Taurog. 1990. Spontaneous inflammatory disease in transgenic rats expressing HLA-B27 and human beta 2m: an animal model of HLA-B27-associated human disorders. Cell. 63:1099-1112.

24. Taurog, J.D., S.D. Maika, W.A. Simmons, M. Breban, and R.E. Hammer. 1993. Susceptibility to inflammatory disease in HLA-B27 transgenic rat lines correlates with the level of B27 expression. J. Immunol. 150:4168-4178.

25. Taurog, J.D., J.A. Richardson, J.T. Croft, W.A. Simmons, M. Zhou, J.L. Fernandez Sueiro, E. Balish, and R.E. Hammer. 1994. The germfree state prevents development of gut and joint inflammatory disease in HLA-B27 transgenic rats. J. Exp. Med. 180:2359-2364.

26. Brinster, R.L., H.Y. Chen, M.E. Trumbauer, M.K. Yagle, and R.D. Palmiter. 1985. Factors affecting the efficiency of introducing foreign DNA into mice by microinjecting eggs. Proc. Natl. Acad. Sci. USA. 82:4438-4442.

27. MacDonald, T.T., and P.B. Carter. 1978. Contact sensitivity in germfree mice. J. Reticuloendothel. Soc. 24:287-293.

28. Orcutt, R.P., F.J. Gianni, and R.J. Judge. 1987. Development of an "altered Schaedler flora" for NCI gnotobiotic rodents. Microecol. Ther. 17:59a. (Abstr.)

29. Grisham, M.B., J.N. Benoit, and D.N. Granger. 1990. Assessment of leukocyte involvement during ischemia and reperfusion of intestine. Methods Enzymol. 186:729-742.

30. Siegling, A., M. Lehmann, C. Platzer, F. Emmrich, and H.D. Volk. 1994 A novel multispecific competitor fragment for quantitative PCR analysis of cytokine gene expression in rats. J. Immunol. Methods. 177:23-28.

31. Crofford, L.J., H. Sano, K. Karalis, E.L. Webster, E.A. Goldmuntz, G.P. Chrousos, and R.L. Wilder. 1992. Local secretion of corticotropin-releasing hormone in the joints of Lewis rats with inflammatory arthritis. J. Clin. Invest. 90:2555-2564

32. Dijkema, R., H. van der Meide, M. Dubbeld, M.W. Caspers, Jr., and H. Schellekens. 1986. Cloning, expression and purification of rat IFN gamma. Methods Enzymol. 119:453-463.

33. Eisenberg, S.P., M.T. Brewer, E. Verderber, P. Heimdal, B.J. Brandhuber, and R.C. Thompson. 1991. Interleukin 1 receptor antagonist is a member of the interleukin 1 gene family: evolution of a cytokine control mechanism. Proc. Natl. Acad. Sci. USA. 88:5232-5236.

34. Kwon, J., I. Chung, and E. Benveniste. 1993. Cloning and sequence analysis of the rat tumor necrosis factor-encoding gene. Gene. 132:227-236. 
35. Herfarth, H.H., S.P. Mohanty, H.C. Rath, S. Tonkmogy, and R.B. Sartor. 1996. Interleukin-10 suppresses chronic, experimental granulomatous inflammation induced by bacterial cell wall polymers. Gut. In press.

36. Nishida, T., N. Nishino, M. Takano, Y. Sekiguchi, K. Kawai, K.O. Mizuno, S. Nakai, Y. Masui, and Y. Hirai. 1989. Molecular cloning and expression of rat interleukin 1 alpha cDNA. J. Biochem. 105:351-357.

37. Nudel, U., R. Zakut, M. Shani, S. Neuman, Z. Levy, and D. Vaffe. 1983. The nucleotide sequence of the rat cytoplasmatic beta-actin gene. Nucleic Acids Res. 11:1759-1771.

38. Sadlack, B., H. Merz, H. Schorle, A. Schimpl, A.C. Feller, and I. Horak. 1993. Ulcerative colitis-like disease in mice with a disrupted interleukin-2 gene. Cell. 75:253-261.

39. Kühn, R., J. Löhler, D. Rennick, K. Rajewsky, and W. Müller. 1993. Interleukin-10-deficient mice develop chronic enterocolitis. Cell. 75:263-274.

40. Rath, H.C., D.E. Bender, L.C. Holt, T. Grenther, J.D. Taurog, R.E. Hammer, and R.B. Sartor. 1995. Metronidazole attenuates colitis in HLA-B27/ $\mathrm{h} \beta 2$ microglobulin transgenic rats: a pathogenic role for anaerobic bacteria. Clin. Immunol. Immunopathol. 76:S45. (Abstr.)

41. Bjarnason, I., J. Hayllar, P. Smethurst, A. Price, and M. J. Gumpel. 1992. Metronidazole reduces intestinal inflammation and blood loss in non-steroidal anti-inflammatory drug induced enteropathy. Gut. 33:1204-1208.

42. Videla, S., J. Vilaseca, F. Guarner, A. Salas, F. Treserra, E. Crespo, M. Antolin, and J.R. Malagelada. 1994. Role of intestinal microflora in chronic inflammation and ulceration of the rat colon. Gut. 35:1090-1097.

43. Wells, C.L., M.A. van de Westerlo, R.P. Jechorek, B.A. Feltis, T.D. Wilkins, and S.L. Erlandsen. 1996. Bacteroides fragilis enterotoxin modulates epithelial permeability and bacterial internalization by HT-29 enterocytes. Gastroenterology. 110:1429-1437.

44. Davis, S.W., L.C. Holt, and R.B. Sartor. 1990. Luminal bacteria and bacterial polymers potentiate indomethacin-induced intestinal injury in the rat. Gastroenterology. 98:444a. (Abstr.)

45. Lichtman, S.N., E.E. Okoruwa, J. Keku, J.H. Schwab, and R.B. Sartor. 1992. Degradation of endogenous bacterial cell wall polymers by the muralytic enzyme mutanolysin prevents hepatobiliary injury in genetically susceptible rats with experimental intestinal bacterial overgrowth. J. Clin. Invest. 90:1313-1322.

46. Shull, M.M., I. Ormsby, A.B. Kier, S. Pawlowski, R.J. Diebold, M. Yin,

R. Allen, C. Sidman, G. Proetzel, D. Calvin, N. Annunziata, and T. Doetsch- man. 1992. Targeted disruption of the mouse transforming growth factor-beta 1 gene results in multifocal inflammatory disease. Nature (Lond.). 359:693-699.

47. Oberhuber, G., C. Püspök, C. Oesterreicher, R. Maier-Dobersberger, F. Pfeffel, G. Novacek, J. Hammer, C. Zauner, A. Kummer, H. Vogelsang, R. Pötzi F. Wrba, and T. Radasziewics. 1996. Crohn's disease of the stomach is histologically characterized by focal active gastritis. Gastroenterology. 110:982a. (Abstr.)

48. Aiko, S., and M.B. Grisham. 1995. Spontaneous intestinal inflammation and nitric oxide metabolism in HLA B27 transgenic rats. Gastroenterology. 109: $142-150$.

49. Sartor, R.B. 1994. Cytokines in intestinal inflammation: pathophysiological and clinical considerations. Gastroenterology. 106:533-539.

50. Herfarth, H.H., and R.B. Sartor. 1994. Cytokine regulation of experimental intestinal inflammation. Curr. Opin. Gastroenterol. 10:625-632.

51. Esser, R.E., S.A. Stimpson, W.J. Cromartie, and J.H. Schwab. 1985. Reactivation of streptococcal cell wall-induced arthritis by homologous and heterologous cell wall polymers. Arthritis Rheum. 28:1402-1411.

52. Stimpson, S.A., R.E. Esser, P.B. Carter, R.B. Sartor, W.J. Cromartie and J.H. Schwab. 1987. Lipopolysaccharide induces recurrence of arthritis in rat joints previously injured by peptidoglycan-polysaccharide. J. Exp. Med. 165: 1688-1702.

53. Sartor, R.B., H.C. Rath, S.N. Lichtman, and E.A.F. van Tol. 1996. Animal models of intestinal and joint inflammation. Bailliere's Clin. Rheumatol. 10: $55-76$.

54. Sartor, R.B., T.M. Bond, and J.H. Schwab. 1988. Systemic uptake and intestinal inflammatory effects of luminal bacterial cell wall polymers in rats with acute colonic injury. Infect. Immun. 56:2101-2108.

55. Lichtman, S.N., J. Keku, J.H. Schwab, and R.B. Sartor. 1991. Evidence for peptidoglycan absorption in rats with experimental small bowel bacterial overgrowth. Infect. Immun. 59:555-562.

56. Granfors, K., S. Jalkanen, R. Von Essen, R. Lahesmaa-Rantala, O. Isomaki, K. Pekkola-Heino, R. Merilahti-Palo, R. Saario, H. Isomaki, and A. Toivanen. 1989. Yersinia antigens in synovial-fluid cells from patients with reactive arthritis. N. Engl. J. Med. 320:216-221.

57. Granfors, K., S. Jalkanen, A.A. Lindberg, O. Mäki-Ikola, R. Von Essen, R. Lahesmaa-Rantala, H. Isomaki, R. Saario, W.J. Arnold, and A. Toivanen. 1990. Salmonella lipopolysaccharide in synovial cells from patients with reactive arthritis. Lancet. 335:685-688. 